\title{
Stator Design Aspects for Permanent Magnet Super- conducting Wind Power Generators
}

\author{
Kaihe Zhang, Xiaoyan Huang, Lijian Wu, Youtong Fang and Wenping Cao
}

\begin{abstract}
This paper presents an electromagnetic design of a permanent magnet superconducting wind power generator with different stator teeth structures and armature winding arrangements. The main contribution of this work is that a novel stator configuration is proposed, which is beneficial for superconducting machines. The topology of tapering poles makes it possible for the machine to carry larger current without severe magnetic saturation in the stator teeth. Meantime, the distributed arrangement of wires in the stator slot can reduce the $\mathrm{AC}$ loss in the same output power condition. Finite element analysis with commercial software is used to support these results.
\end{abstract}

Index Terms-AC loss, stator, superconducting, wind power generation.

\section{INTRODUCTION}

$\mathbf{W}$ IND power generation is a promising topic of research and engineering. Considerable wind farms particularly large scale offshore ones have been built in the past few years because of their high powers and stable operating characteristics. However, the extremely huge sizes of these machines also have drawbacks such as expensive transportation and installation costs. One of the potential techniques to reduce the volume and weight of these giant generators is to adopt high temperature superconducting (HTS) materials. According to the American Renewable Energy Laboratory, HTS generators could be superior to permanent magnet (PM) ones in terms of weight and drive train cost if the turbine power is above 8 MW [1].

The current capacity of HTS wires or bulks could be 100 times larger than that of copper, which can be utilized to generate magnetic fields of fairly high values. Based on this feature, many electromagnetic designs of multi-megawatt superconducting generators have been presented [2]-[4]. The normal flux density of HTS field windings can be as large as $4 \mathrm{~T}$. But the rotating cryogenic systems of these windings in the rotor are complicated and hard to realize. Hence, the concept of introducing HTS armature windings into PM generators in order to increase the power density can be studied [5], [6]. According to [7], power capacity of this kind of machine is basically restricted by three factors, which are the quench of su-

This work was supported in part by the National Natural Science Foundation of China under Grant 51477149.

Kaihe Zhang, Xiaoyan Huang, Lijian Wu, Youtong Fang are with the College of Electrical Engineering, Zhejiang University, Hangzhou 310007, China (e-mail xiaoyanhuang@zju.edu.cn). Wenping Cao is with Aston University, Birmingham United Kingdom, B4 7ET. perconductivity, irreversible demagnetization of PM poles and severe saturation of ferromagnetic materials. Further researches such as parametric analysis and optimal design can be focused on these aspects in order to find the fundamental power limit of PM HTS wind power generators. Besides, some novel structures which are not commonly used in PM machines can be considered when designing HTS machines in order to obtain higher power capacity.

For the proposed generator, the armature current and applied magnetic field are large and alternating, which can lead to AC loss. This kind of loss should be evaluated thoroughly. Some formulas for calculating the AC loss of HTS machines have been derived and applied in both analytical and numerical models [8]-[10]. In addition, some special techniques such as using ferromagnetic materials [6] can be utilized to reduce the field applied on the HTS materials and AC loss consequently. But the influences of HTS wire arrangement were not analyzed in previous literature reviews. The impact of distribution of conductors in stator slot could be explored for lower $\mathrm{AC}$ loss and better efficiency.

In this paper, a 7 MW PM HTS wind power generator with different shapes of stator teeth and armature winding arrangement is presented. Compared with other machines, the proposed one has higher power density and lower AC loss. Section II describes the structure and parameters of the proposed generator and Section III gives the power capacity based on the new stator teeth shape. Then the arrangement of HTS wires is discussed in Section IV. Finally, conclusions are drawn in Section V.

\section{STRUCTURE AND PARAMETERS}

Diagram model of the PM HTS wind power generator is shown in Fig. 1. The proposed generator is a direct-drive permanent magnet machine with concentrated armature windings and surface mounted magnet poles designed previously. Several optimal variables such as the slot opening ratio are also marked in Fig. 1 and will be discussed later.

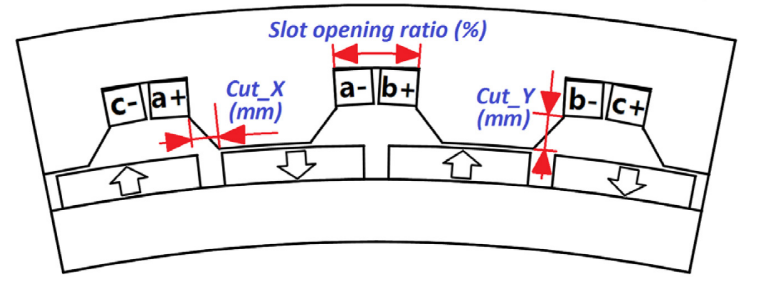

Fig. 1. 1/16 model of the proposed PM HTS wind power generator. 
TABLE I

SPECIFIC PARAMETERS OF THE GENERATOR

\begin{tabular}{cc}
\hline \hline Variable & Value \\
\hline Rated output power & $7 \mathrm{MW}$ \\
Rated speed & $10 \mathrm{rpm}$ \\
Frequency & $5.333 \mathrm{~Hz}$ \\
Outer diameter & $5 \mathrm{~m}$ \\
Active length & $2 \mathrm{~m}$ \\
Number of slots & 48 \\
Number of poles & 64 \\
Air-gap length & $6 \mathrm{~mm}$ \\
Air-gap diameter & $4630 \mathrm{~mm}$ \\
Slot opening ratio & $26 \%-58 \%$ \\
Stator yoke width & $85 \mathrm{~mm}$ \\
Magnet height & $45 \mathrm{~mm}$ \\
Magnet embrace & $85 \%$ \\
\hline \hline
\end{tabular}

TABLE II

SPECIFIC PARAMETERS OF THE HTS WIRES [11]

\begin{tabular}{cc}
\hline \hline Parameter & Value \\
\hline HTS wire source & Hyper Tech, USA \\
Strand diameter & $0.83 \mathrm{~mm}$ \\
Wire diameter & $2.49 \mathrm{~mm}$ \\
Number of strands & 7 \\
Number of filaments & 36 \\
Critical current $(20 \mathrm{~K})$ & $6000 \mathrm{~A}$ \\
Operating current $(20 \mathrm{~K})$ & $1360 \mathrm{~A}$ \\
\hline \hline
\end{tabular}

Specific parameters of the proposed generator are listed in Table I and details about the $\mathrm{MgB}_{2}$ wires selected as the armature windings are listed in Table II. The operating current can be as large as $1360 \mathrm{~A}$, making it possible to obtain higher output power with the same magnetic load. Electrical frequency is selected to be low for less AC losses. Besides, another important design variable is the slot opening ratio. The stator teeth will suffer from severe magnetic saturation if armature current becomes extremely high after using $\mathrm{MgB}_{2}$. Hence, this variable should be optimized in order to balance the current capacity of HTS materials and the electromagnetic performance of stator iron.

\section{DESIGN AND OPTIMIZATION}

Optimization is an essential process when designing electrical machines and some optimization methods such as multidisciplinary and multilevel methods are presented in [12]-[13]. In this paper, enumeration method is utilized in order to find out the best parameters and obtain better knowledge of the influence of every parameter. During the design and optimization process, the optimization objective is output power density of the proposed generator. The constraints are selected as magnetic saturation of stator teeth, irreversible demagnetization of PM poles and quench of superconductivity. The optimization parameters are the slot opening ratio, Cut_X and Cut_Y. These parameters are analyzed separately. More specifically, all the other parameters are kept unchanged when varying one particular parameter.

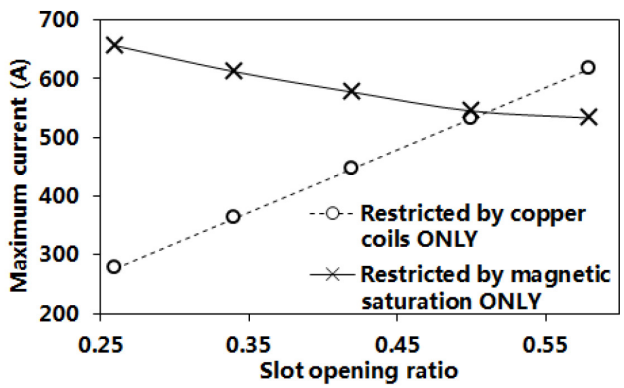

Fig. 2. Variations of maximum armature current with slot opening ratio on different kinds of restrictions.

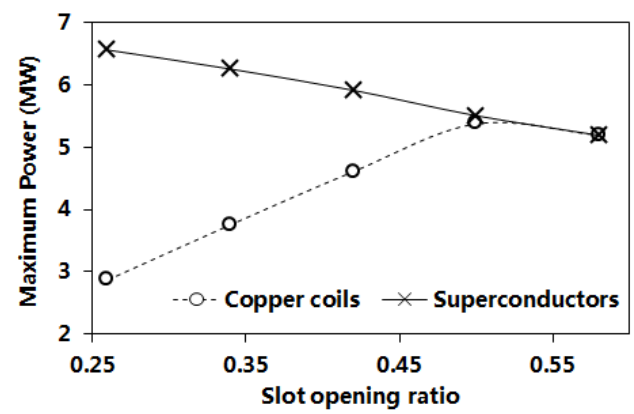

Fig. 3. Variations of maximum electromagnetic power with slot opening ratio for copper and superconducting armature windings.

\section{A. Slot Opening Ratio}

As discussed above, the slot opening ratio was modified from $26 \%$ to $58 \%$ during the design and optimization process in this paper. For conventional generators with copper armature windings, the slot opening ratio influences the cross section area of copper wire or the number of conductors per slot directly, which can affect the maximum armature current as well. As shown in Fig. 2, the maximum armature current increases when slot opening ratio becomes larger. But on the restriction of magnetic saturation, the upper limit of current has the opposite trend. The reason is that larger slot opening ratio means thinner stator teeth and heavier distribution of flux density with the same magnetic load. Hence, the optimized slot opening ratio is around $50 \%$ where the restriction of both the copper cross area and the magnetic saturation are the same.

However, for generators with $\mathrm{MgB}_{2}$ armature windings, the upper limit of the superconducting armature current does not depend on the slot area. The current is restricted by magnetic saturation only. It can be observed from Fig. 3 that the maximum electromagnetic power of HTS machines is higher than that of conventional ones for small slot opening ratios. But the values will become the same if the slot opening ratio exceeds $50 \%$. This is because that magnetic saturation dominates the restriction on armature current at that point. The electromagnetic power of the generator with $\mathrm{MgB}_{2}$ windings can be as high as $6.5 \mathrm{MW}$ while the maximum power of a conventional generator can be only around 5.4 MW.

\section{B. Pole Tapering}

Pole tapering is an effective way to improve the magnetic circuit. This kind of structure could also be introduced into HTS machines in order to increase the power density. 


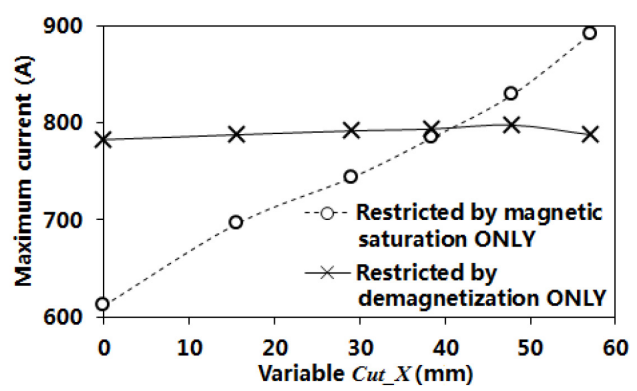

Fig. 4. Variations of maximum armature current with $C u t X$ on different kinds of restrictions.

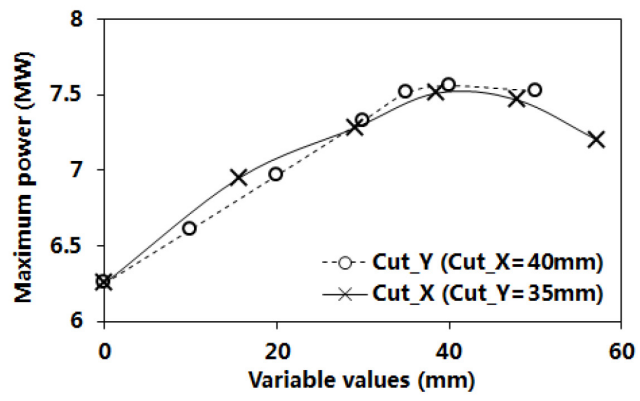

Fig. 5. Variation of maximum electromagnetic power with $C u t_{-} X$ and $C u t_{-} Y$.

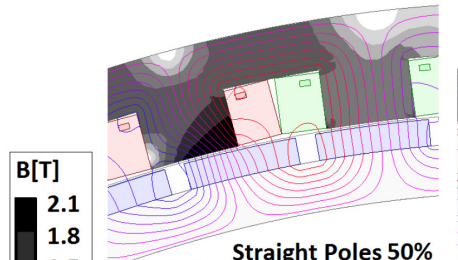

(a) $\mathrm{I}=535 \mathrm{~A}, \mathrm{P}=5.4 \mathrm{MW}$

\begin{tabular}{r|}
1.2 \\
0.9 \\
0.6 \\
0.3 \\
0
\end{tabular}

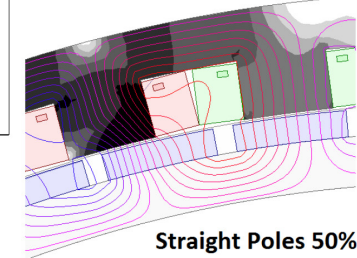

(c) $\quad \mathrm{l}=785 \mathrm{~A}, \mathrm{P}=7.7 \mathrm{MW}$

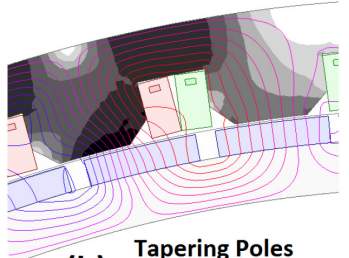

(b) $\begin{aligned} & \text { Tapering Poles } \\ & \mathrm{l}=785 \mathrm{~A}, \mathrm{P}=7.5 \mathrm{M}\end{aligned}$

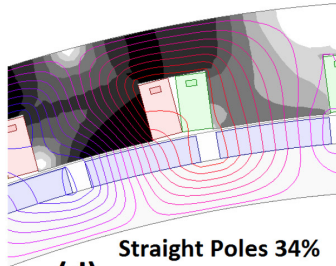

(d) $I=785 \mathrm{~A}, P=7.8 \mathrm{MW}$
Fig. 6. Distributions of flux density and flux lines for different structures of the proposed generator.

The design variables $C u t \_X$ and $C u t_{-} Y$ shown in Fig. 1 determine the specific tapering shape of the stator teeth. Topology of tapering poles means that the width of the teeth becomes thinner at the ending part. It is also obvious that both of these two variables are zero for common stator teeth, which can be called straight poles as well. This kind of structure makes it possible for the stator to carry higher current without severe magnetic saturation. As shown in Fig. 4, the maximum armature current can be higher for larger values of $\mathrm{Cut}_{-} X$ on the restriction of magnetic saturation only. But the current cannot increase over $785 \mathrm{~A}$ considering the irreversible demagnetization of PM poles because it leads to breakdown of the machine. Hence, the best values of variables Cut_X and $\mathrm{Cut}_{-} Y$ should be the values calculated on the restrictions of not only magnetic saturation but also demagnetization of PMs. According to the results in Fig. 5, these optimized values are $40 \mathrm{~mm}$ and 35 $\mathrm{mm}$ respectively.

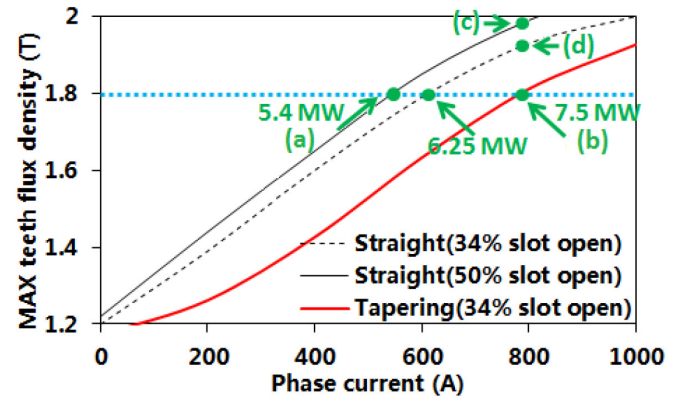

Fig. 7. Variation of maximum teeth flux density with current.

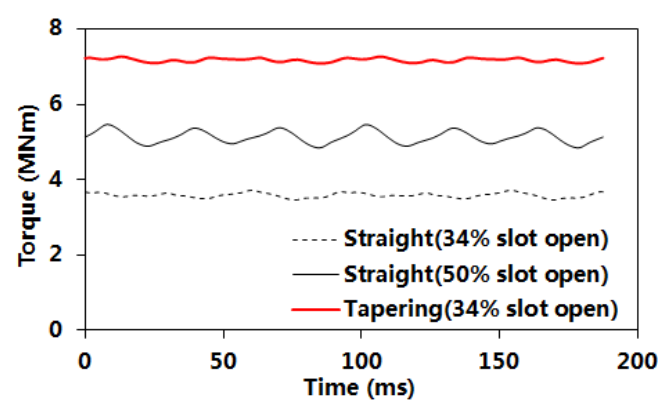

Fig.8. Waveforms of electromagnetic torque for different machine structures and parameters.

\section{Power and Torque Capacity}

Higher armature current means larger electromagnetic power or torque when there is no severe magnetic saturation and irreversible demagnetization. It can be observed from Fig. 6 (a) and (b) that the flux density distributions in the main parts of stator teeth are similar to each other. But armature current capacity of the generator with tapering poles is 1.5 times higher than that in Case (a), which makes the electromagnetic power increased to almost 7.5 MW. However, if the current is raised to $785 \mathrm{~A}$ which is as high as that in Case (b), the flux density in the main parts of stator teeth will be above $1.8 \mathrm{~T}$ even for the generator with a small slot opening ratio as shown in Fig. 6 (c) or (d). Hence, the current of generators with straight poles cannot be designed very large, making the electromagnetic power performance inferior to those with tapering poles.

In addition, the four cases discussed above can be presented more clearly by Fig. 7. Technology of pole tapering makes it possible for the armature windings to carry the highest current without magnetic saturation. In contrast, the current capacity is lower for those with straight poles. The highest power for HTS machines utilizing straight poles with $50 \%$ and $34 \%$ slot opening ratios are only 5.4 MW and 6.25 MW respectively. Besides, the proposed generator has lower torque ripple as shown in Fig. 8, which is another advantage of pole tapering.

\section{SUPERCONDUCTING WINDINGS}

\section{A. AC Loss Calculation}

AC loss can be generated in HTS materials which are exposed to varying magnetic field or carrying AC. It should be investigated thoroughly when designing HTS machines. 


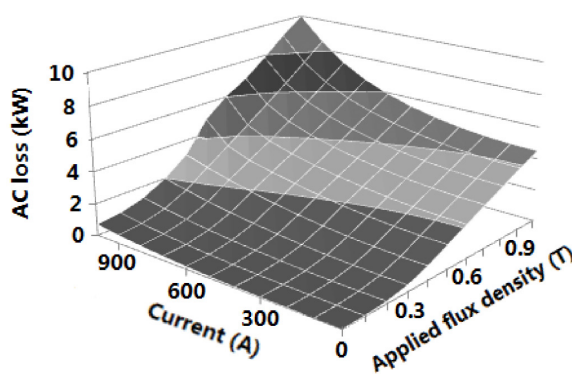

Fig. 9. Variations of AC loss calculated using analytical models with applied flux density and current.

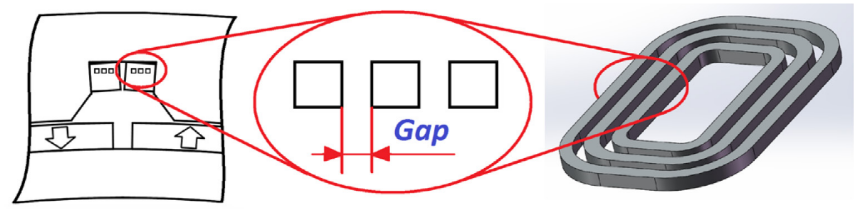

Fig. 10. Specific model of the distributed HTS wires in stator slot.

The formulas based on the Critical-State-Model and Norris Model [8] are utilized to calculate AC loss of the proposed generator. Three basic factors can affect the value of this kind of loss which are frequency, applied flux density and current. The operating frequency is set to be a constant in this paper. Thus, AC loss is mainly determined by the applied flux density and current. Fig. 9 shows its variation tendency. It can be observed from the results that the applied flux density has dominant influence on AC loss. Hence, the arrangements of $\mathrm{MgB}_{2}$ wires in the stator slot are worth considering in order to minimize the flux density applied on the windings and the overall AC loss consequently.

\section{B. Winding Structures}

The flux density applied on the HTS windings consists of two parts. One part is excited by the PMs in the rotor and the other part is generated by the armature windings. Considering this feature, every coil can be divided into many small distributed areas as shown in Fig. 10 in order to reduce the flux density induced by the high current. In this paper, one coil is separated evenly into three smaller coils and variable Gap denotes the interval between them.

Fig. 11 shows the calculated AC losses with different values of the variable Gap. For conventional concentrated arrangement of HTS wires, Gap equals zero and the calculated value of AC loss is the highest, which is almost $5.5 \mathrm{~kW}$. As a matter of fact, the cryogenic power can be fairly high because the temperature is $20 \mathrm{~K}$. Hence, the overall efficiency of the generator with conventional winding arrangement is calculated as $96.4 \%$. However, the value of AC loss will decrease apparently if Gap becomes larger. The reason for this improvement is that the applied flux density has lower values when the armature current is distributed into many smaller domains. The AC loss can be reduced by $20 \%$ when utilizing a group of coaxial coils instead of one solid coil, and the efficiency of the proposed generator can be improved to $97.2 \%$.

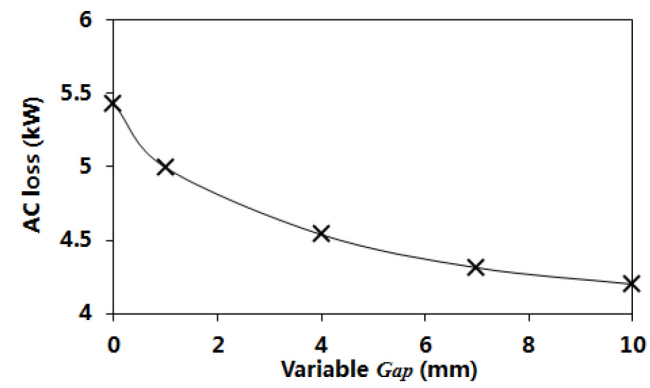

Fig. 11. Variation of calculated AC loss of the proposed generator with the design variable Gap.

\section{CONCLUSION}

Utilization of superconducting technology can improve the power density of wind power generators. This paper presents a stator design of a 7 MW HTS PM machine with higher output power capacity, lower AC loss and better efficiency. Future works will be focused on faster and more effective optimization methods.

\section{REFERENCES}

[1] R. Qu, Y. Liu, and J. Wang, "Review of superconducting generator topologies for direct-drive wind turbines," IEEE Trans. Appl. Supercond., vol. 23, no. 3, Jun. 2013, Art. ID 5201108.

[2] Y. Guan, Z. Q. Zhu, Z. Azar, A. S. Thomas, et al., "Comparison of electromagnetic performance of 10-MW superconducting generators with different topologies for offshore direct-drive wind turbines," IEEE Trans. Appl. Supercond., vol. 27, no. 7, Oct. 2017, Art. ID 5204211.

[3] H. Karmaker, M. Ho, and D. Kulkarni, "Comparison between different design topologies for multi-megawatt direct drive wind generators using improved second generation high temperature superconductors," IEEE Trans. Appl. Supercond., vol. 25, no. 3, Jun. 2015, Art. ID 5201605.

[4] J. Jin, Y. Tang, X. Xiao, B. Du, et al., "HTS power devices and systems: principles, characteristics, performance, and efficiency," IEEE Trans. Appl. Supercond., vol. 26, no. 7, Oct. 2016, Art. ID 3800526.

[5] Y. Jiang, R. Pei, W. Xian, Z. Hong, and T. A. Coombs, "The design, magnetization and control of a superconducting permanent magnet synchronous motor," Supercond. Sci. Technol., vol. 21, Art. no. 065011, 2008.

[6] L. Li, J. Cao, B. Kou, Z. Han, et al., "Design of the HTS permanent magnet motor with superconducting armature winding," IEEE Trans. Appl. Supercond., vol. 22, no. 3, Jun. 2012, Art. ID 5200704.

[7] K. Zhang, Y. Gao, Y. Fang, X. Huang, et al., "Design of a $10 \mathrm{MW}$ dualstator superconducting permanent magnet wind power generator," Int. Conf. Elect. Mach. Systems, Chiba, Japan, 13-16 Nov. 2016, Art. no. 0519 .

[8] W. T. Norris, "Calculation of hysteresis losses in hard superconductors carrying ac: isolated conductors and edges of thin sheets," J. Phys. D: Appl. Phys., vol. 3, pp. 489-507, 1970.

[9] D. Kostopoulos, D. Liu, G. Genani, H. Polinder, "Feasibility study of a $10 \mathrm{MW} \mathrm{MgB}_{2}$ fully superconducting generator for offshore wind turbines," European Wind Energy Association Offshore Conf., Frankfurt, Germany, 19-21 Nov. 2013, Art. no. 408.

[10] B. Shen, J. Li, J. Geng, L. Fu, et al., "Investigation of AC losses in horizontally parallel HTS tapes," Supercond. Sci. Technol., vol. 30, Art. no. 075006, 2017.

[11] S. S. Kalsi, "Superconducting wind turbine generator employing $\mathrm{MgB}_{2}$ windings both on rotor and stator," IEEE Trans. Appl. Supercond., vol. 24, no. 1, Feb. 2014, Art. ID 5201907.

[12] G. Lei, T. Wang, Y. Guo, J. Zhu, and S. Wang, "System-level design optimization methods for electrical drive systems: deterministic approach," IEEE Trans. Ind. Electron., vol. 61, no, 12, pp. 6591-6602, Dec. 2014.

[13] G. Lei, C. Liu, J. Zhu, and Y. Guo, "Techniques for multilevel design optimization of permanent magnet motors," IEEE Trans. Energy Convers., vol. 30, no. 4, pp. 1574-1584, Dec. 2015. 